\title{
BLICKDIAGNOSE
}

\section{Kollision mit Kleiderhaken}

\section{Hier steht eine Anzeige.}

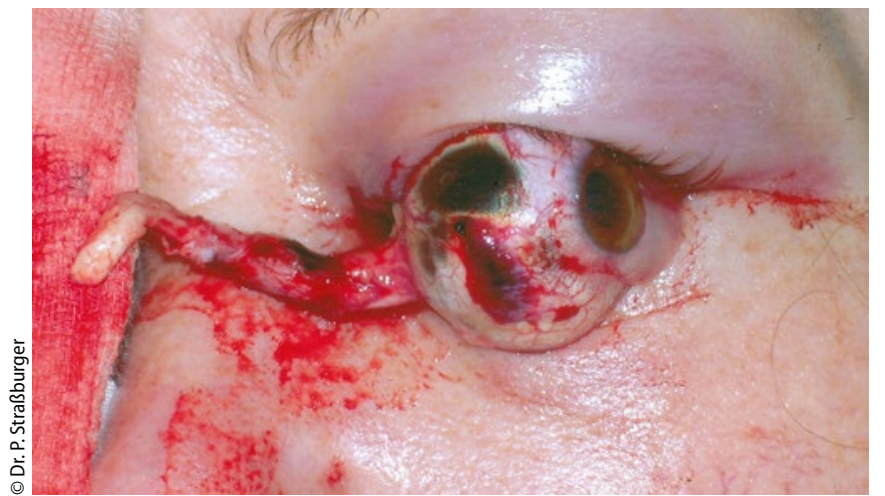

\author{
Springer
}

Z.n. Sturz mit komplett ausgerissenem Sehnerv und subtotaler Enukleation.

— Eine 52-jährige Frau wird vom Notarzt zu Hause in der Wohnung liegend aufgefunden. Bei Einlieferung in der Klinik ist sie ansprechbar. Sie gibt an, zu Hause in der Wohnung gestürzt zu sein. Sie sei im Flur auf einen Kleiderhaken gefallen.

\section{Was ist passiert?}

Es handelt sich um eine traumatische Enukleation des linken Auges (Abb. 1). Der Bulbus ist durch die Tenonkapsel noch adhärent, aber in der vertikalen Achse um etwa $90^{\circ}$ auswärts rotiert. Der Sehnerv ist in der Tiefe abgerissen und liegt durch die Rotation des Bulbus sichtbar dem Nasenrücken auf.

\section{Wie ging es weiter?}

Die Aufnahmeuntersuchung mit cCT erbrachte keinen Hinweis auf Frakturen oder intrakranielle Blutungen, das Chiasma war in der Bildgebung auf der betroffenen Seite leicht anterograd verschoben. Eine orientierende Überprüfung brachte initial einen intakten Visus des Partnerauges. Die Laboruntersuchung zeigte einen Blutalkoholgehalt von 2,43\% auf.

In Vollnarkose wurde die notfallmäßige Versorgung mit vollständiger Enukleation durchgeführt. Nach Resektion des zerrissenen Tenongewebes konnte der Bulbus vollständig entfernt werden. Weiterhin wurde eine Orbitaplombe eingesetzt, darüber ließen sich Tenon und Bindehaut gut adaptieren, sodass in den Folgewochen die Anpassung einer Prothese möglich war. 